\title{
Dynamic layout planning and its role in producing world class of products
}

\author{
K. Rahmani ${ }^{\mathrm{a}}$, E. TaghiPour ${ }^{\mathrm{b}}$ and A. R. Valyani ${ }^{*}$
}

${ }^{a}$ Department of Management, Tabriz Branch, Islamic Azad University, Tabriz, Iran

${ }^{b}$ Department of Industrial Management, Tabriz Branch, Islamic Azad University, Tabriz, Iran

${ }^{c}$ Department of Industrial Management, East Azerbaijan Science and Research Branch, Islamic Azad University, Tabriz, Iran.

\section{H R O N I C L E}

Article history:

Received December 18, 2014

Accepted March 102015

Available online

March 112015

Keywords:

Manufacturing in world class

Dynamic layout planning

Flexibility

\begin{abstract}
A B S T R A C T
Today, due to rapid changes in the world, the infrastructure should be designed to produce goods in world class. Dynamic layout planning increases flexibility and reduces the cost of new products. Investigating the essential factors to achieve world-class shows that dynamic layout planning plays essential role on flexibility, cost reduction, implementation of worldclass producing techniques, reduction of product delivery time, customer satisfaction, and management in multiple and worldwide locations. The purpose of this study was to investigate the role of dynamic layout planning on production of world class products in some firms located in province of Zanjan, Iran. Using Spearman correlation test, the study indicated that dynamic layout planning played an important role in delivering the products to the world-class level.
\end{abstract}

\section{Introduction}

During the past few decades, there have been tremendous changes on business environment conditions, which requires operating the organizations in a competitive environment using world-class ideologies. A world-class manufacturer is able to produce goods using the latest flexible manufacturing techniques. To achieve this flexibility, the foundation of company should be designed to handle the dynamics of the company. In recent years, dynamic layout planning has been proposed to achieve this objective. The problem of facility layout is a strategic issue and has a significance effect on efficiency of production systems. Dynamic layout planning compensates the effects of fluctuating demand and changing conditions (Rosenblatt, 1986). In this paper, the role of dynamic layout planning in achieving the world-class condition is investigated.

The term "world class manufacturing” was first introduced by Hayes and Wheelwright (1984); after that, several researchers have developed the concept. Schonberger (1986) classified the principles of manufacturing in world-class in eight categories including human resources, quality and process improvement, design, general, operations, information operations and control, advertising and

* Corresponding author

E-mail address: Amirreza.Valyani@gmail.com (A.R. Valyani) 
marketing. Schonberger requested the managers to evaluate their firms according to these principles and improve these methods to remain in the global competition. Also, in order to have global competition, they should be able to use special techniques. These techniques included: "The timely manufacturing, quality circles, materials planning, flexible manufacturing systems, computer aided design, computer aided manufacturing, computer integrated manufacturing, manufacturing resource planning, comprehensive quality control, maintenance of productivity, business process reengineering, planning of organization resources and supply chain capacity and electronic commerce”.

World class manufacturing activities determine necessary activities to stay in the global competitive condition; also, with the use of modern and optimized techniques, the ability to solve problems has been increased (Hayes \& Wheelwright, 1984). Based on the nature and the period, the layout can be classified into static and dynamic. In the static approach, the flow between the equipment is constant and it is determined for a period and the demand for product mix in the investigated period is assumed to be constant; however, if the layout is changed periodically according to demand, the layout has to be dynamic. Many researches have investigated static layout. A comprehensive review of research on the static layout can be found in Meller and Gau (1996). According to Lcochhar and Heragu (1999), static layout has two assumptions: First, product demand is constant and product mix is also constant. Due to fluctuations in product demand and changes in product mix, transportation prices are fluctuate and usually increase. In addition, the introducing of new products or changing the new product changes the transportation facility. These changes lead to an inefficient layout and transportation costs for facility and materials will increase; under this condition, the change in layout is necessary (Afentakis et al., 1990). With increasing the demand for products, companies have to plan to meet demands. To deal with these challenges, the layout should be flexible and in easily shaped. A good arrangement for some circles is related to the product demand assessment, and flow between the units and assessment of the time is required for re-design (Benjaffar \& Sheikhzadeh, 2000). This leads to the need for facility layout algorithms to deal with the combined product. Redesign of the existing arrangement is acceptable only when it yields a significant reduction in the cost of materials. In recent years, significant efforts have been accomplished to solve the dynamic arrangement of the facility. Rosenblat (1986) developed a procedure for determining the optimal arrangement for a number of periods by considering the cost of transportation of materials and the cost of redesign.

Approaches to solve the problems of facility layout is divided into two categories: In the first case, the layout has been developed for multiple products and in the latter one is flexible or agile (Kochhar \& Heragu, 1999). Therefore, it is easy to deal with changes to the product.The first approach assumes that the product information for some period in the early design stages is known. The solution includes a basic layout that optimizes the cost (Rosenblatt, 1987). The second approach assumes that the layout will adapt according to changing moment and it is recommended if the significant changes in product and demand mix exist. Optimization and heuristic approaches are reapplied to optimize the cost of transport and layout (Yang \& Peters, 1998).

Change in the layout provides two types of costs including the stop operation costs and the cost of the facility from the current position to the new position. The costs of new arrangement can be classified into fixed costs and variable costs. Fixed cost is due to production decrease in opening the machine and re-assembly and it is not associated with new and existing layout. The variable cost is associated with the current and future position of facility (Kochhar \& Heragu, 1999).

\subsection{Factors influencing facility layout change}

There are some reasons to make changes in the facility layout as follows,

\section{Cost reduction}

The facility layout includes the position of cells, units or vehicles in the manufacturing hall. More options in facility layout emphasizes in reduction of transport expenses. Transportation costs includes 20 to 50 percent of the cost of the facility is operational alignment (Tompkins \& White, 1996). 
Changes in demand or product

Production facility is directly or indirectly affected by demand. This issue can also change the process order.

\section{Changes in the planning and order of process}

This issue is a strong factor on building the distance between the handling and transportation costs. Changes in planning will influence on changes in AGV's.

\section{Changes in resources}

Machinery, facility and materials in vehicles that are the company's assets, influence on the arrangement of the work facilities.

\section{Changes in standards and safety regulations}

Safety regulations in each country has resulted in specific standards for the installation and deployment of safety devices and facility height.

\subsection{Methods for solving dynamic layout}

Today, manufacturing companies must have the ability to respond quickly to changes in demand and the volume and type of product. On average, 40 percent of a company's sales is obtained by the new product (Yang \& Peters, 1998). Thus, changes in the type and rate of the device influences on the layout. About one third of US companies are organized every two years (Yang \& Peters, 1998). The first extensive research on solving the problems of dynamic layout was accomplished by Rosenblat (1986) with emphasis on dynamic programming. Later, better ways related to the heuristic dynamic planning methods were introduced. Urban (1993) proposed exchange stage heuristic method in a clockwise manner similar to CRAft method.

Many people have tested several methods of mathematical programming. Conway and Venkataramanan (1994) proposed genetic algorithm for solving dynamic layout problems. Dunker et al. (2005) proposed a combination of dynamic programming algorithm and a genetic algorithm to solve the dynamic layout problems. Kochhar and Heraga (1999) developed a method for installation of facility to meet the need and demand variability and change on the product based on the genetic algorithm heuristic method. Simulated annealing method is a stochastic optimization technique. If the structure of data and the neighborhood is properly defined, it is a good method for layout optimization (Baykasoglu \& Gindy, 2001). The behavior of ants to find the shortest distance between food source and colony is the development foundation for a method called a hybrid ant colony system (McKendall \& Shang, 2006). By comparing the results obtained from the proposed method in solving the layout facility problem, there was no significant difference between the qualities of methods. However, in solving the problem with high size, the methods based in ant colony algorithm are preferred compared with the methods based on genetic algorithm (Baykasoglu \& Gindy, 2001). Although it is not able to perform better than dynamic programming and simulated annealing in solving the large size problems (Erel et al., 2003).

\subsection{The basic components of a world-class organizations management and manufacturing in world- class}

World-class competitiveness in the global market means that companies are successful in the competition. It means that they are superior than or equal their competitor in terms of quality, waiting time, flexibility, cost and pricing, customer service, and innovation. Each of the key components is 
presented with a brief description of how they affect the manufacturing organizations and their competitiveness (Farsijani, 2005).

\section{Reducing waiting time}

In the world market, the manufacturer with the ability to transport goods faster will be more successful against competitors with similar characteristics of the product, price and quality. In other markets, fast transport, can certainly increase customer satisfaction (Farsijani, 2005). In all cases, shorter waiting times increase flexibility and reduce risk.

\section{Research hypotheses}

The research hypotheses includes a main hypothesis which is divided into six sub-hypotheses. Subhypotheses includes the main components for achieving the global class.

The main hypothesis: There is a relationship between the dynamic layout planning and achieving to the world-class.

Sub-hypothesis 1.1: There is a significant relationship between dynamic layout planning and production cost reduction.

Sub-hypothesis 1.2: There is a significant relationship between dynamic layout planning and flexibility. Sub-hypothesis 1.3: There is a significant relationship between dynamic layout planning and customer satisfaction.

Sub-hypothesis 1.4: There is a significant relationship between dynamic layout planning and production of time of delivery.

Sub-hypothesis 1.5: There is a significant relationship between dynamic layout planning and better implement of world-class manufacturing techniques.

Sub-hypothesis 1.6: There is a significant relationship between dynamic layout planning and management in globally and multiple locations.

As the objective of this study was to answer to an applied question in real situations, and finally it improves the methods of planning and increases productivity, this is an applied research and on the other hand, because the relationship between the independent variable (dynamic layout plan) and the dependent variable (manufacturing in world class of products) is investigated so, this research is a correlation type.

The research population consisted of 30 patients with a high school graduate who are employed in Saba Tire Yarn and Takestan Pars Crankshaft manufacturing complexes and also 30 members of mechanical and civil engineers who are members of related engineering association in the city of Zanjan, Iran.

In this study, after an extensive study of the literature and articles in the field of advanced manufacturing management, a total of 30 questions were posed. Heavily relying on the literature and the opinions of experts in the field, confirmed the validity of the content. To assess the reliability, coefficient of Cronbach alpha by applying SPSS 17 software was used and it was calculated as 0.74, which was increased to 0.80 by the removal of the 3 questions. Table 1 demonstrates the summary of Cronbach alpha for all components of the survey.

\section{Table 1}

Cronbach alpha for research variables

\begin{tabular}{lcccccc}
\hline Variable & $\begin{array}{c}\text { Cost of } \\
\text { Manufacturing }\end{array}$ & Flexibility & $\begin{array}{c}\text { Customer } \\
\text { Satisfaction }\end{array}$ & $\begin{array}{c}\text { Reduce } \\
\text { delivery time }\end{array}$ & $\begin{array}{c}\text { Production } \\
\text { techniques }\end{array}$ & $\begin{array}{c}\text { Management in } \\
\text { multiple locations }\end{array}$ \\
\hline Cronbach alpha & 0.76 & 0.79 & 0.74 & 0.76 & 0.81 & 0.75 \\
\hline
\end{tabular}




\section{Results and discussion}

In this step, first the normality of the data was examined, so the Kolmogorov-Smirnov test was used for this purpose and assumptions and the table below shows a summary of the test. Table 2 demonstrates the result of our survey.

$\mathrm{H}_{0}$ : The data follow a normal distribution.

$\mathrm{H}_{1}$ : The data do not follow a normal distribution

\section{Table 2}

Results of statistical test for investigating the normal distribution of research components

\begin{tabular}{lcc}
\hline Research components & K-S & Significance level \\
\hline Cost of Manufacturing & 2.180 & 0.00 \\
Flexibility & 2.746 & 0.00 \\
Customer Satisfaction & 3.010 & 0.00 \\
Reduce delivery time & 2.329 & 0.00 \\
Production techniques & 2.832 & 0.00 \\
Management in multiple locations & 1.546 & 0.03 \\
\hline
\end{tabular}

As can be observed from the results of Table 2, because the significance level of the test is less than 0.05 , therefore, based on the assumption of normality of the research components $\mathrm{H}_{0}$ cannot be verified. Therefore, in the present study, due to the lack of normality of studied sample, the nonparametric tests and specifically the Spearman correlation coefficient is used. The results of correlation analysis between variables and rejection of the null hypothesis and verifying the claim hypothesis are presented in Table 3. According to this table, all claim hypotheses are verified. According to Table 4, the hypotheses are ranked in terms of the correlation coefficient. According to this table, all the coefficients are positive. The highest coefficient is related to sub-hypothesis 1.2 and the highest coefficient is related to sub-hypothesis 1.6. The relationship between the flexibility factor that is an important prerequisite to achieve world class and the dynamic layout planning is because it is synonymous with the term dynamism and flexibility and dynamism of one factor is directly related to its flexibility.

\section{Table 3}

Research hypotheses test

\begin{tabular}{lcc}
\hline Hypotheses & Sig. & Final situation \\
\hline Sub-hypothesis 1.1 & 0.000 & Verified \\
Sub-hypothesis 1.2 & 0.000 & Verified \\
Sub-hypothesis 1.3 & 0.000 & Verified \\
Sub-hypothesis 1.4 & 0.000 & Verified \\
Sub-hypothesis 1.5 & 0.000 & Verified \\
Sub-hypothesis 1.6 & 0.000 & Verified \\
\hline
\end{tabular}

According to the literature it was expected that the factor of customer satisfaction be the last one because this factor is associated indirectly with dynamic layout planning and management of multiple and global locations are associated directly with dynamic layout planning but the results of a questionnaire analysis rated the last one to management of multiple and global locations.

\section{Table 4}

Ranking correlation coefficients

\begin{tabular}{lcc}
\hline Hypotheses & Correlation coefficient & Ranking \\
\hline Sub-hypothesis 1.1 & 0.71 & 2 \\
Sub-hypothesis 1.2 & 0.73 & 1 \\
Sub-hypothesis 1.3 & 0.59 & 5 \\
Sub-hypothesis 1.4 & 0.63 & 4 \\
Sub-hypothesis 1.5 & 0.65 & 3 \\
Sub-hypothesis 1.6 & 0.42 & 6 \\
\hline
\end{tabular}




\section{Conclusion}

The results show that the dynamic layout planning maintained a significant positive relationship with the flexibility, cost reduction, better implementation of world class manufacturing techniques, reduction of product delivery time, customer satisfaction, and management of multiple and worldwide locations, respectively. These factors are the main parameters to achieve the world class. Due to changes in product and demand, without having a dynamic layout and a periodic change, it is not possible to survive in such competitive market. In the provided methods, there is a good solutions to analyze and calculate the costs which is recommended in further researches.

\section{References}

Afentakis, P., Millen, R.A. and Solomon, M.N. (1990). Dynamic layout strategies for flexible manufacturing systems. International Journal of Production Research, 28(2), 311-323.

Baykasoğlu, A., \& Gindy, N. N. (2001). A simulated annealing algorithm for dynamic layout problem. Computers \& Operations Research, 28(14), 1403-1426.

Benjaafar, S., \& Sheikhzadeh, M. (2000). Design of flexible plant layouts. Iie Transactions, 32(4), 309322.

Conway, D. G., \& Venkataramanan, M. A. (1994). Genetic search and the dynamic facility layout problem. Computers \& Operations Research, 21(8), 955-960.

Dunker, T., Radons, G., \& Westkämper, E. (2005). Combining evolutionary computation and dynamic programming for solving a dynamic facility layout problem. European Journal of Operational Research, 165(1), 55-69.

Erel, E., Ghosh, J. B., \& Simon, J. T. (2003). New heuristic for the dynamic layout problem. Journal of the Operational Research Society, 54(12), 1275-1282.

Farsijani, H. (2005) Challenges of producing world class. Tadbir magazine. 155. (In Persian).

Hayes, R.H. and Wheelwright, S.C. (1984), Restoring Our Competitive Edge: Competing Through Manufacturing, Wiley, New York, NY

Kochhar, J., \& Heragu, S. S. (1999). Facility layout design in a changing environment. International Journal of Production Research, 37(11), 2429-2446.

McKendall, A. R., \& Shang, J. (2006). Hybrid ant systems for the dynamic facility layout problem. Computers \& Operations Research, 33(3), 790-803.

Meller, R. D., \& Gau, K. Y. (1996). The facility layout problem: recent and emerging trends and perspectives. Journal of manufacturing systems, 15(5), 351-366.

Rosenblatt, M. J. (1986). The dynamics of plant layout. Management Science,32(1), 76-86.

Rosenblatt, M. J., \& Lee, H. L. (1987). A robustness approach to facilities design. International Journal of Production Research, 25(4), 479-486.

Schonberger, R. J. (1986). The vital elements of world-class manufacturing. International Management, 41(5), 76-78.

Tompkins, J. A., White, J. A., Bozer, Y. A., \& Tanchoco, J. M. A. (2010).Facilities planning. John Wiley \& Sons.

Urban, T. L. (1993). A heuristic for the dynamic facility layout problem. IIE transactions, 25(4), 5763.

Yang, T., \& Peters, B. A. (1998). Flexible machine layout design for dynamic and uncertain production environments. European Journal of Operational Research, 108(1), 49-64. 